\title{
BIOWAIVER STUDY OF ORAL TABLETTED ETHYLCELLULOSE MICROCAPSULES OF A BCS CLASS I DRUG
}

\author{
Ghulam Murtaza , Mahmood Ahmad and Naveed Akhtar \\ Department of Pharmacy, Faculty of Pharmacy and Alternative Medicines, The Islamia \\ University of Bahawalpur, Bahawalpur 63100, Pakistan
}

(Received August 17, 2008; revised March 4, 2009)

\begin{abstract}
This article describes the preparation and characterization (in vitro and in vivo) of three different sustained-release salbutamol sulfate-ethylcellulose tabletted microparticles $\left(T_{1}, T_{2}\right.$ and $\left.T_{3}\right)$ and reference sustained release tablet (Ventolin $8 \mathrm{mg} \mathrm{SR}$, GSK). In vitro characterization included dissolution study, scanning electron microscopy, UV and FTIR spectroscopy, X-ray diffractometry and thermal analysis. A validated HPLCfluorescent detection method was adopted to conduct bioavailability studies in young healthy human volunteers. The microparticles exhibited an irregular and slightly aggregated morphology with fine rheological properties. No strong chemical interaction was found between drug and polymer. A good linear correlation $\left(\mathrm{R}^{2}=0.9224,0.945\right.$, 0.9363 and 0.9694 for $T_{1}, T_{2}, T_{3}$ and reference formulations, respectively) was obtained between the percent cumulative drug released (in vitro) and the percent cumulative drug absorbed (in vivo) data of these formulations at specific time points to develop level $\mathrm{A}$ in vitro-in vivo correlation. However, $\mathrm{T}_{2}$ was found closer to the reference formulation that shows a reliable prediction of the plasma concentrations obtained following a single dose of salbutamol sulfate modified release formulations.
\end{abstract}

KEY WORDS: Salbutamol sulfate, Tabletted microcapsules, In vitro-in vivo correlation

\section{INTRODUCTION}

Food and Drug Administration Authority (FDA) has developed a regulatory guidance for both immediate- and modified-release dosage forms to reduce the requirement of bioavailability studies as part of the formulation design and optimization. Increased development of modifiedrelease dosage forms necessitates investigating the broader aspects of in vitro-in vivo correlation (IVIVC). Biopharmaceutical Classification System (BCS) represents a criterion for the classification of drugs on the basis of their solubility and permeability. In principle, BCS Class I (highly soluble and highly permeable) active pharmaceutical ingredients (APIs) have been identified to be eligible for the BCS-based biowaiver approach. If a class I drug is microencapsulated and converted into a slow release multi-unit dosage form in which the release profile controls the rate of absorption, and the solubility and permeability of the drug is site independent, an IVIVC is expected, otherwise limited or no correlations. In this continuity, present article also describes the development of an IVIVC for tabletted microcapsules of a water soluble drug (salbutamol sulfate) [1-3].

Salbutamol sulfate (SS), a BCS class I drug, is a strong $\beta-2$ agonist that is used for the treatment of asthma. Its oral absorption is good. Its biological half-life is about 4 to 6 hours [4].

Ethylcellulose (EC) with complete ethoxyl substitution (DS = 3) is $\mathrm{C}_{12} \mathrm{H}_{23} \mathrm{O}_{6}\left(\mathrm{C}_{12} \mathrm{H}_{22} \mathrm{O}_{5}\right)_{n} \mathrm{C}_{12} \mathrm{H}_{23} \mathrm{O}_{6}$ where " $\mathrm{n}$ " can vary to provide a wide variety of molecular weights. Ethylcellulose, an ethyl ether of cellulose, is a long chain polymer of $\beta$-anhydroglucose units joined together by acetal linkages. Its ability to absorb pressure during tabletting, nontoxicity, biocompatibility and non-biodegradability are the reasons of its extensive selection for the development of tablet dosage forms, especially sustained release formulations [5].

Some researchers have microencapsulated salbutamol sulfate into various polymers by different techniques, i.e. SS into EC by coacervation-temperature change and solvent

*Corresponding author. E-mail: gmdogar356@gmail.com 
evaporation and into poly(lactic-co-glycolic acid) (PLGA) by solvent evaporation but none of them characterized morphology, rheological properties, Fourier Transform infra-red (FTIR) spectroscopy, X-ray diffractometry and thermal analysis [6-7]. These studies are presented in this paper. In the present study, SS-EC microparticles prepared by non-solvent addition-phase separation varying EC ratio were tabletted and evaluated by various mathematical, statistical and analytical approaches followed by the development of IVIVC.

\section{EXPERIMENTAL}

\section{Materials}

Salbutamol sulfate (Unexo Laboratories, Lahore, Pakistan), ethyl cellulose (22 cp, Sigma, USA), polyisobutylene (PIB, M.W. 2.800, Acros Organics, USA), petroleum ether (40-60 ${ }^{\circ} \mathrm{C}, \mathrm{BDH}$, England), methanol, toluene (Merck, Germany) and all other chemicals of analytical grade were purchased through commercial sources.

\section{Preparation and characterization of microparticles}

SS-EC microparticles were prepared by non-solvent addition coacervation techniques varying drug polymer ratio by $1: 1,1: 2$ and 1:3. The morphology of prepared microparticles was determined by scanning electron microscope (SEM) [8]. Rheological properties of microparticles were also studied. FTIR spectroscopy and X-ray diffractometry of SS and its microparticles was carried out to study the effect of microencapsulation process on crystallinity of drug and to identify any drug polymer interaction. Thermal analysis was also carried out as it is an important tool for studying cross-linking of EC molecules with drug, compound (SS and EC) degradation temperatures and absorbed moisture content of materials.

\section{Preparation of tabletted microparticles}

Each batch of microparticles was mixed with $1 \%$ Talc, $0.5 \%$ magnesium stearate, $10 \%$ starch and lactose (used as filler). Each mixture was compressed into tablets having a weight of 200 $\mathrm{mg}$, by direct compression on a single punch tablet machine. The microparticles containing 9.6 mg SS equivalent to $8 \mathrm{mg}$ salbutamol were present in each tablet of SS. $\mathrm{T}_{1}, \mathrm{~T}_{2}$ and $\mathrm{T}_{3}$ tabletted microcapsules contained microparticles with 1:1, 1:2, and 1:3 SS-EC ratio. Three batches of tablets were prepared for each formulation of SS. Assay of SS, encapsulation efficiency and production yield of prepared microparticles was also estimated [9-11].

\section{Physicochemical evaluation of tabletted microparticles}

The tabletted microparticles were evaluated physically with respect to their weight variation, hardness, friability and thickness using suitable instruments [12].

In vitro dissolution study of various tabletted microparticles was conducted using United State Pharmacopoeia (USP) XXIV apparatus II (rotating paddle, six replicates, Pharma test, Germany) and samples were drawn at pre-determined time intervals $(0,0.5,1,1.5,2,3,4,6,8$, 10 and 12 hours) after filtration through millipore filters followed by UV spectrophotometeric analysis [13]. Dissolution media (distilled water, $0.1 \mathrm{M} \mathrm{HCl}$ and $\mathrm{pH} 6.8$ buffer) and stirring speed $(50,100$ and $150 \mathrm{rpm})$ were also varied to study their influence on dissolution behavior. 
Mathematical analysis

Model dependent approaches. Five model-dependent approaches (zero order, first order, Higuchi, Hixson-Crowell and Korsmeyer-Peppas) were used to compare drug dissolution profiles and interpret drug release kinetics with the help of equations 1-5.

Zero order kinetic model [14]: $\quad \mathrm{M}_{\mathrm{t}}=\mathrm{M}_{\mathrm{o}}+\mathrm{K}_{\mathrm{o}} \mathrm{t}$

First order kinetic model [14]:

$$
\ln \mathrm{M}_{\mathrm{t}}=\ln \mathrm{M}_{\mathrm{o}}+\mathrm{K}_{1} \mathrm{t}
$$

Higuchi Kinetic model [15]:

$$
\mathrm{M}_{\mathrm{t}}=\mathrm{M}_{\mathrm{o}}+\mathrm{K}_{\mathrm{H}} \mathrm{t}_{1 / 2}
$$

Hixson-Crowell kinetic model [16]: $\quad \mathrm{M}_{\mathrm{o}}{ }^{3}-\mathrm{M}_{\mathrm{t}}{ }^{3}=\mathrm{K}_{\mathrm{HC}} \mathrm{t}$

Korsmeyer-Peppas kinetic model [17]: $\quad \mathrm{M}_{\mathrm{t}} / \mathrm{M}_{\alpha}=\mathrm{K}_{\mathrm{kp}} \mathrm{t}^{\mathrm{n}}$

$\mathrm{M}_{\mathrm{t}}$ is the cumulative amount of drug released at any specified time point and $\mathrm{M}_{\mathrm{o}}$ is the initial amount of drug in the formulation. $\mathrm{K}_{\mathrm{o}}, \mathrm{K}_{1}, \mathrm{~K}_{\mathrm{H}}, \mathrm{K}_{\mathrm{HC}}$ and $\mathrm{K}_{\mathrm{kp}}$ are rate constants for zero order, first order, Higuchi, Hixson-Crowell and Korsmeyer-Peppas models, respectively. In equation (5), $M_{t} / M_{\alpha}$ is the fraction of the drug release at time $t$ and $n$ is the release exponent that characterizes different release mechanisms. The $\mathrm{n}$-value is calculated from the slope of Korsmeyer-Peppas plot.

Model independent approaches. One way analysis of variance (ANOVA) plus Post-Hoc analysis (Duncan and Tukey H.S.D.) for significance at $p<0.05$ was conducted for whole release profiles using SPSS version 12.0 [18]. Pair wise procedures include the difference factor $\left(f_{l}\right)$ (Equation 6) and the similarity factor $\left(f_{2}\right)$ (Equation 7). According to the FDA guidance, values of $f_{1}$ between zero and 15 and of $f_{2}$ between 50 and 100 ensure sameness or equivalence of the two dissolution profiles. In both equations, $R_{t}$ and $T_{t}$ represent the dissolution measurements at $\mathrm{P}$ time points of the reference and test, respectively [19].

$$
\begin{aligned}
& f_{1=}\left\{\left[\sum_{i=1}^{P}\left|\mathrm{R}_{\mathrm{t}}-\mathrm{T}_{\mathrm{t}}\right|\right] /\left[\sum_{i=1}^{P} \mathrm{R}_{\mathrm{t}}\right]\right\} \\
& f_{2}=50 \log \left\{\left[1+(1 / \mathrm{P}) \sum_{i=1}^{P}\left(\mathrm{R}_{\mathrm{t}}-\mathrm{T}_{\mathrm{t}}\right)^{2}\right]^{-1 / 2} * 100\right\}
\end{aligned}
$$

Estimation of swelling and erosion of tabletted microparticles

SS-EC tabletted microparticles were also evaluated for their swelling and erosion behavior to verify anomalous diffusion [20]. Each tablet matrix was weighed before and after dissolution in above mentioned specific conditions for particular time and after drying at $40{ }^{\circ} \mathrm{C}$ for $48 \mathrm{~h}$ to determine their erosion. Swelling $(\%)$ and erosion $(\%)$ was estimated by following formulas:

$$
\begin{aligned}
& \text { Swelling }(\%)=\mathrm{S} / \mathrm{R} \times 100 \\
& \text { Erosion }(\%)=(\mathrm{T}-\mathrm{R}) / \mathrm{T} \times 100
\end{aligned}
$$

where $\mathrm{T}$ is the initial weight of the matrix; $\mathrm{S}$ is the weight of the matrix after swelling; and $\mathrm{R}$ is the weight of the eroded matrix. 
Bioavailability studies

Twenty four healthy male adult non-smoker Pakistani human subjects weighing (61-85 kg) and having no clinical and biological abnormality were selected after screening through haemodynamic, haematological and urinalytical evaluation and divided into 4 groups (A, B, C and $\mathrm{D}$ ), each consisting of 6 subjects. In first sampling, group $\mathrm{A}, \mathrm{B}$ and $\mathrm{C}$ received $\mathrm{T}_{1}, \mathrm{~T}_{2}$ and $\mathrm{T}_{3}$ formulations, respectively, and $4^{\text {th }}$ group received reference one (Ventolin $8 \mathrm{mg} \mathrm{SR}$, Glaxosmithkline, Pakistan) with water after a full night fast while complete sampling schedule is given below.

\begin{tabular}{|l|l|l|l|l|}
\hline Formulation & Sampling 1 & Sampling 2 & Sampling 3 & Sampling 4 \\
\hline Formulation $\mathrm{T}_{1}$ & Group A & Group D & Group C & Group B \\
\hline Formulation $\mathrm{T}_{2}$ & Group B & Group A & Group D & Group C \\
\hline Formulation $\mathrm{T}_{3}$ & Group C & Group B & Group A & Group D \\
\hline Formulation Reference & Group D & Group C & Group B & Group A \\
\hline
\end{tabular}

A wash out period of one week was set between each sampling phase. Lunch and dinner was provided after $4 \mathrm{~h}$ and $8 \mathrm{~h}$ post dosing time, respectively. The ethics of this study were approved by the Board of Advance Studies and Research, The Islamia University of Bahawalpur. After drug administration, $5 \mathrm{~mL}$ blood samples were drawn through an indwelling intravenous canula at a pre-dose and at $0,0.5,1.0,1.5,2.0,3.0,4.0,5.0,6.0,8.0,10.0,12.0$ and $24 \mathrm{~h}$ followed by centrifugation immediately at $3500 \mathrm{rpm}$ for 10 minutes. Plasma was separated and stored at -20 ${ }^{\circ} \mathrm{C}$ until analysis.

\section{Chromatographic conditions}

Analyses were performed by method developed in our laboratory using high-performance liquid chromatography (HPLC) (Agilent, USA) with fluorescent detector operated at excitation wavelength $228 \mathrm{~nm}$ and emission wavelength $310 \mathrm{~nm}$. A Lichrosorb RP-C18 stainless steel analytical column $(4.6 \times 200 \mathrm{~mm}, 5 \mu \mathrm{m})$ (Agilent, USA) was used. HPLC system was operated at room temperature $\left(\sim 20{ }^{\circ} \mathrm{C}\right)$. Mobile phase of following composition $\mathrm{CH}_{3} \mathrm{OH}:\left(\mathrm{NH}_{4}\right) \mathrm{H}_{2} \mathrm{PO}_{4}$ $(67 \mathrm{mM})\left(\mathrm{pH} 3.0\right.$ adjusted with $\left.\mathrm{H}_{3} \mathrm{PO}_{4}\right)$ : TEA, 44.5:55.5:0.02 (v/v/v \%) was prepared, filtered through cellulose acetate filter $(0.45 \mu \mathrm{m}$ pore size, Sartorius, AG37070 Goettingen, Germany) and degassed by sonicator (T490DH, Elma, Germany) at $70 \mathrm{~Hz}$ before use. Mobile phase was delivered at a rate of $0.7 \mathrm{~mL} / \mathrm{min}$. Injection volume was $100 \mu \mathrm{L}$.

\section{Pharmacokinetic analysis}

Previously obtained data was tabulated in a Microsoft Excel worksheet and plasma drug concentration-time curve was plotted and different pharmacokinetic parameters, i.e. area under curve (AUC), time to reach maximum concentration $\left(\mathrm{t}_{\max }\right)$ and maximum plasma concentration $\left(\mathrm{C}_{\max }\right)$, etc, were evaluated.

The cumulative amount of drug absorbed $(\%)$ at time $t$ was calculated by Wagner-Nelson method [1]:

Percent absorbed $=\left\{\left(\mathrm{C}(\mathrm{t}) / \mathrm{K}_{\mathrm{e}}+\mathrm{AUC}_{(0-\mathrm{t})} / \mathrm{AUC}_{(0-\infty)}\right) \times 100\right.$

where, $\mathrm{C}_{\mathrm{t}}$ is plasma concentration at time $\mathrm{t}$ and $\mathrm{K}_{\mathrm{e}}$ is elimination rate constant. AUC $(0-\mathrm{t})$ and $\mathrm{AUC}_{(0-\infty)}$ represent the area under the curve from zero to time $t$ and infinity, respectively. 
Internal prediction error

In vivo properties of a drug can be predicted from its relevant initial in vitro dissolution performance by evaluating predictive mathematical IVIVC model, known as internal predictability. Following approach, based on AUC, is used to evaluate the error in internal predictability [1]:

Percent prediction error $=\left[\left(\mathrm{AUC}_{\text {observed }}-\mathrm{AUC}_{\text {predicted }}\right) / \mathrm{AUC}_{\text {observed }}\right] \times 100$

\section{RESULTS AND DISCUSSION}

The study focused on the effect of SS and EC ratio, dissolution media and stirring speed. The SEM results, drug-polymer interaction study and release profiles of tabletted microparticles are shown in Figure 1 to 5. Table 1 represents pharmacokinetic parameters of salbutamol sulfate after a single sustained release oral dose of different formulations of salbutamol sulfate administered to human volunteers. Percent erosion and swelling character of optimum formulation $\mathrm{T}_{2}$ is presented in Figure 6. Figure 7 and Figure 8 shows IVIVC for different formulations.

Entrapment efficiency $(\%)$ and production yield (\%) of microparticles was found to be approximately $97 \%$ and $98 \%$, respectively. The microparticles were whitish, aggregated and irregular in shape (Figure 1). Rheological properties of all formulations are expressed in terms of bulk density, taped density, compressibility index, Hausner's ratio and angle of repose. It was observed that bulk density decreased with the increase in drug polymer ratio. Present results are in agreement with previous observation where it was also reported that bulk density increased when the polymer concentration was decreased [21]. Compressibility index of all six formulations is below $15 \%$ indicating excellent flow properties. Hausner's ratio and angle of repose were below 1.29 and $30^{\circ}$, respectively, for all formulated microparticles again indicating their free flow nature [21].

Table 1. Pharmacokinetic parameters of salbutamol sulfate after a single sustained release oral dose of different formulations of salbutamol sulfate administered to human volunteers.

\begin{tabular}{|c|c|c|c|c|c|}
\hline $\begin{array}{c}\text { Serial } \\
\text { No. }\end{array}$ & Pharmacokinetic parameters & $\begin{array}{c}\text { Observed } \\
\text { values } \\
\text { for } T_{1} \\
\end{array}$ & $\begin{array}{c}\text { Observed } \\
\text { values } \\
\text { for } \mathrm{T}_{2} \\
\end{array}$ & $\begin{array}{c}\text { Observed } \\
\text { values } \\
\text { for } \mathrm{T}_{3} \\
\end{array}$ & Reference \\
\hline 1 & Maximum plasma concentration $\left(\mathrm{C}_{\max }, \mathrm{ng} / \mathrm{mL}\right)$ & 36.06 & 33.63 & 28.43 & 35.74 \\
\hline 2 & Time required for maximum plasma concentration $\left(\mathrm{T}_{\max }, \mathrm{h}\right)$ & 3.0 & 3.0 & 3.0 & 3.0 \\
\hline 3 & Area under curve $_{(\text {total })}\left(\mathrm{AUC}_{(\text {total }),}(\mathrm{ng} \mathrm{h} / \mathrm{mL})\right.$ & 210.70 & 208.75 & 238.71 & 215.69 \\
\hline 4 & Area under momentum curve (total) $\left(\mathrm{AUMC}_{\text {(total) }},\left(\mathrm{ng} \mathrm{h}^{2} / \mathrm{mL}\right)\right.$ & 1502.05 & 1593.79 & 2260.95 & 1506.20 \\
\hline 5 & Percent prediction error & $<10.00$ & $<10.00$ & $<10.00$ & $<10.00$ \\
\hline
\end{tabular}

FTIR spectroscopy

FTIR spectra of SS contained some characteristic and prominent peaks. The spectrum of microparticles also showed amino, hydroxyl and aromatic stretchings at the same values as in that of pure SS which confirmed drug. No significant alteration in the nature of peaks rejected the chances of any strong SS-EC interaction when SS was encapsulated into EC coats. The FTIR spectra of microparticles, drug and polymer are given in Figure 2. 


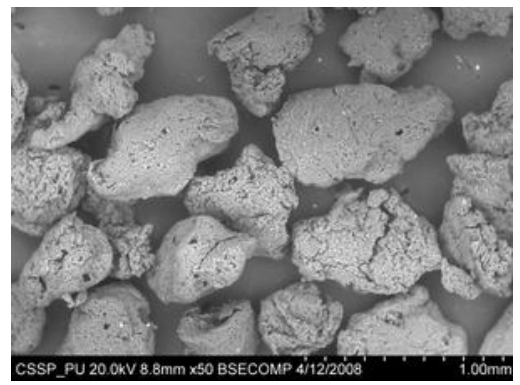

Figure 1.Scanning electron micrographs of salbutamol sulfate-ethylcellulose microparticles segregated from $\mathrm{T}_{2}$ formulation after dissolution.

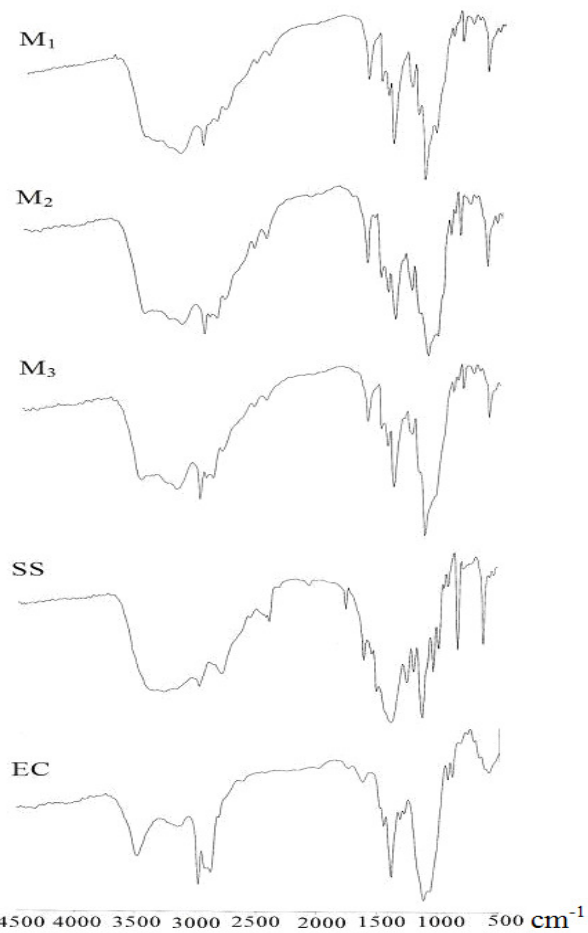

Figure 2. FTIR spectras of ethylcellulose, salbutamol sulfate and microparticles $\left(\mathrm{M}_{1}, \mathrm{M}_{2}\right.$ and $\mathrm{M}_{3}$ ).

\section{Thermal analysis}

The specific and well-recognizable thermal profile of the drug was observed in a specific temperature range. SS microparticles exhibited same thermal characteristics with reduced sharpness. It revealed a significant reduction of drug crystallinity in the polymer matrix attesting the absence of any strong chemical interaction between drug and polymer. Thermal analysis showed good stability of SS in the form of microparticles (Figure 3).

Bull. Chem. Soc. Ethiop. 2009, 23(2) 

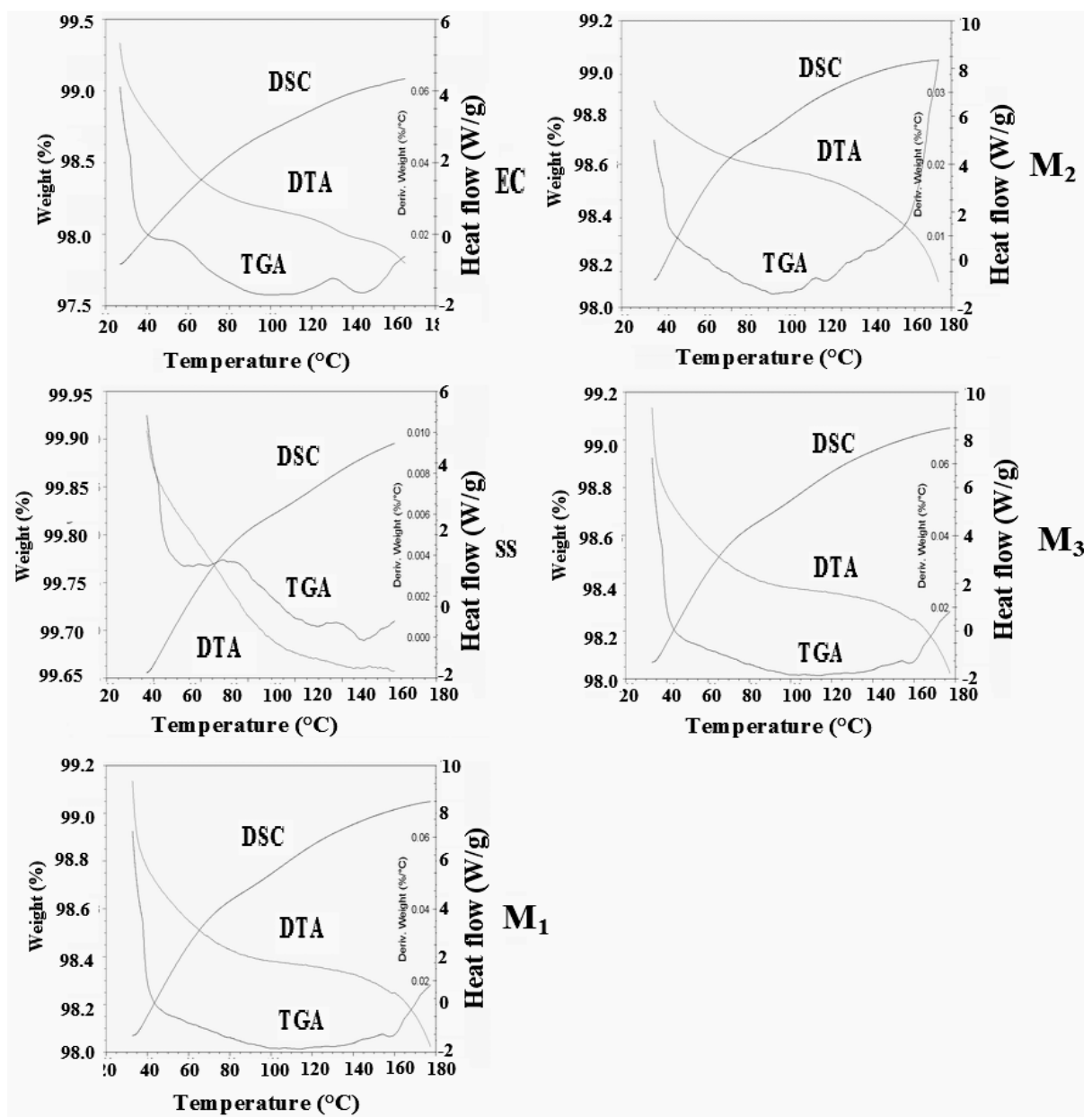

Figure 3. Thermograms of ethylcellulose, salbutamol sulfate and microparticles $\left(\mathrm{M}_{1}, \mathrm{M}_{2}\right.$ and $\left.\mathrm{M}_{3}\right)$.

\section{$X$-ray diffractometry}

X-ray diffractometry revealed amorphous and crystalline nature of pure EC and SS, respectively, as shown in diffractograms (Figure 4). However, a decrease in the signal intensity, i.e. crystallinity of SS was observed in microparticle form as compared to pure components.

\section{Physical characterization of tabletted microparticles}

Physical attributes of the tabletted microcapsules were found to be satisfactory. Tablet hardness varied between $8.3 \pm 1.2$ to $9.5 \pm 1.1 \mathrm{~kg} / \mathrm{cm}^{2}$ and friability was less than $0.5 \%(\mathrm{w} / \mathrm{w})$. The designed tablets showed low weight variation $(< \pm 3.0 \%)$. The average thickness was 3.87 to $3.89 \mathrm{~mm}$. The results fulfilled the requirements of British Pharmacopoeia (BP) [9]. 

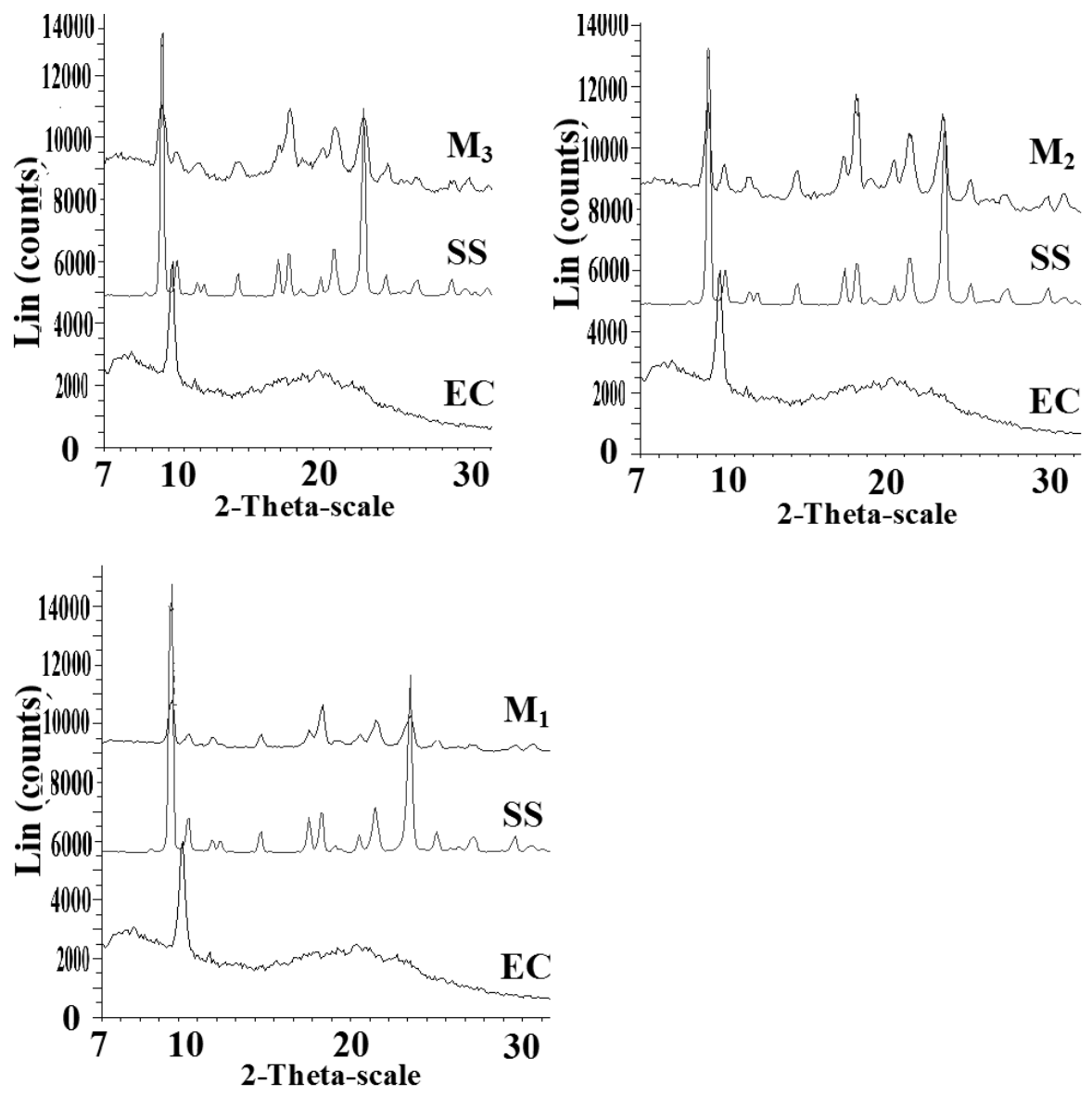

Figure 4. X-Ray diffractograms of ethylcellulose, salbutamol sulfate and microparticles $\left(\mathrm{M}_{1}, \mathrm{M}_{2}\right.$ and $\mathrm{M}_{3}$ ).

\section{Mathematical analysis}

Model independent approaches. The tabletted microparticles were also evaluated for their release profile in double distilled water and were evaluated by different mathematical kinetic models, the difference and similarity factors and one way ANOVA plus Post-Hoc Tests.

Comparison between dissolution profiles of SS tabletted microparticles showed that $60 \%$ release of SS was achieved after 4.78, 6.93 and 11.05 hours from $T_{1}, T_{2}$, and $T_{3}$, respectively [Figure 5]. According to Duncan test, the $\mathrm{t}_{60} \%$ of all batches of the tabletted microparticles lied in the same homogenous group $(1: 1=1: 2=1: 3)(p>0.05)$ whereas Tukey H.S.D. similarized the $t_{60} \%$ of $T_{1}$ and $T_{2}$ and differentiated them from that of $T_{3}$ but not significantly $(p>0.05)$. According to difference factor $\left(f_{l}\right)$ and similarity factor $\left(f_{2}\right)$, the release profiles of following pairs of formulations were different from each other: $T_{1}$ versus $T_{3}$ and $T_{2}$ versus $T_{3}$ as their $f_{l}>$ 15.00 and $f_{2}<50.00$. While $\mathrm{T}_{1}$ versus $\mathrm{T}_{2}$ has $f_{1}<15.00$ and $f_{2}>50.00$ which indicates the mutual similarity of the compared release profiles but to a very less extent. The results indicated that

Bull. Chem. Soc. Ethiop. 2009, 23(2) 
velocity of drug release was slower from tablets with low polymer concentration, i.e. tablet with microparticles having low core to wall ratio and vice versa. It can, therefore, be assumed that decrease in core to wall ratio increased the wall thickness of microparticles and/or decreased the number of surface pores as evident from Figure 1. Moreover, it is reported previously that the release of hydrophilic drugs is mainly controlled by permeation through the water filled channels within the hydrophobic polymer (EC) membrane. It can, therefore, be concluded that both of the above mentioned reasons cause a deceleration in the diffusion of dissolution medium through these channels that consequently decrease the rate of drug release from tabletted microparticles $[6,8,10,22]$.

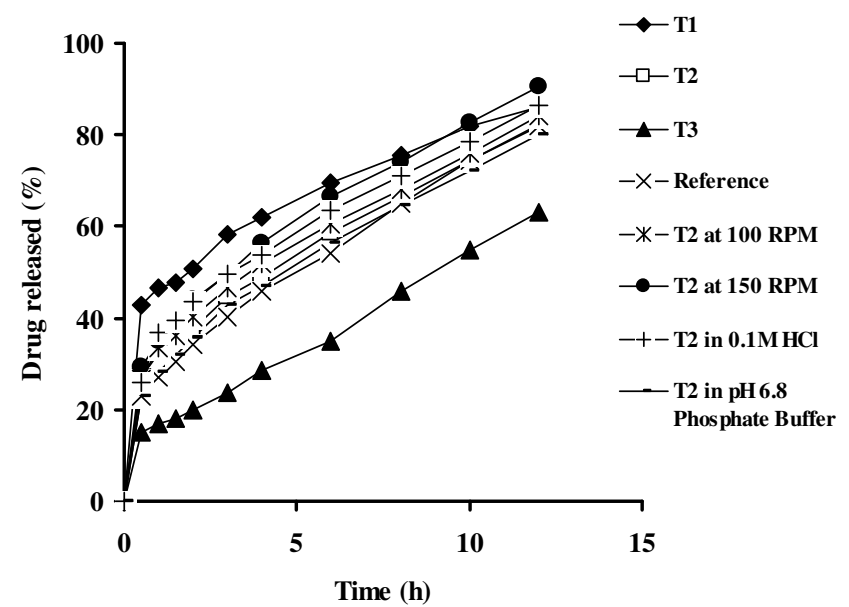

Figure 5. The dissolution profiles of salbutamol sulfate-ethylcellulose tabletted microparticles showing the effect of stirring speed and type of dissolution media on dissolution fashion.

The observed in-vitro drug release profiles from SS tabletted microparticles were biphasic: an initial rapid drug release phase (burst) was followed by the slow and prolonged phase. The burst effect may be beneficial because a high initial release produces an instant effect which can be subsequently maintained for a prolonged period by a slower but continuous release of drug. The rank order of tabletted microparticle for percentage drug burst was as follows: $T_{1}>T_{2}>T_{3}$, also visible from Figure 5. The rapid initial phase of release was thought to occur mainly by dissolution and diffusion of drug entrapped close to or at the surface of microparticles. The second and slower release phase was thought to involve the diffusion of drug entrapped within the inner part of the polymer matrix by means of aqueous channels of a network of pores. It has been already reported that an initial burst effect in release profile was observed especially (a) when the drug solubility is high, (b) loading dose in the polymeric matrix is large and (c) lack of critical polymer concentration. Additionally when polymer concentration is low, the hydrated polymeric matrix would be highly porous leading to rapid diffusion of the drug from the polymeric matrix $[7,23]$.

Model dependent approaches. In order to get meaningful information, the whole drug release profiles were evaluated kinetically and the best fit of the release profiles to the zero order, first order, Higuchi, Hixson-Crowell and Korsmeyer-Peppas models was investigated. Model with the highest co-efficient of determination $\left(\mathrm{R}^{2}\right)$ was judged to be a more appropriate model for the dissolution data. The release profiles from all the formulations were best explained by Higuchi 
model due to the highest linearity, followed by zero order and first order respectively. It suggests that the drug release is controlled by the diffusion of drug through the pores and not through the swollen EC. From Korsmeyer-Peppas model, it is found that the mode of release from all tabletted microparticles was anomalous (non-Fickian, a combination of the diffusion and erosion mechanism) diffusion. The application of the release profiles to Hixson-Crowell equation indicated a change in surface area and diameter of the formulation with the progressive dissolution of the matrix as a function of time.

\section{Estimation of swelling and erosion of tabletted microparticles}

The optimum formulation undergoes swelling and erosion continuously with time (h) after putting into dissolution apparatus (Figure 6). This phenomenon is responsible for the gradual release of drug from tabletted microcapsule matrix. It also confirms anomalous diffusion of SS from tabletted microparticles.

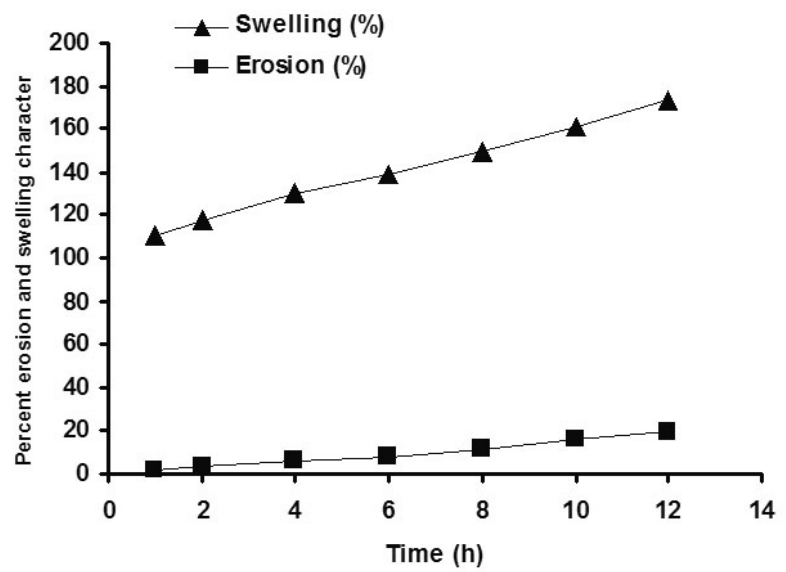

Figure 6. Percent erosion and swelling character of optimum formulation $\mathrm{T}_{2}$. Each data point is a mean \pm S.D. of triplicate measurements $(n=3)$.

Bioavailability studies

The corresponding pharmacokinetic parameters from one-compartmental analysis of the data of all four formulations have been summarized in Table 1 .

In vitro-in vivo correlation for tabletted microparticles

A good correlation between the dissolution and pharmacokinetic data was observed. IVIVC was determined by drawing plots between drug absorbed (\%) and drug dissolved (\%) at same time points for all three formulations. A high value of determination coefficient $\left(R^{2}=0.9224,0.945\right.$, 0.9363 and 0.9694 for $T_{1}, T_{2}, T_{3}$ and reference formulations, respectively) suggested good correlation between in vitro and in vivo profiles (Figure 7 and 8). This correlation shows that dissolution profile can be utilized as a predictive tool for in vivo data. Figure 8 shows a faster SS dissolution rate than its absorption rate. It elaborates that gastric emptying is a rate controlling factor in the absorption of SS from tabletted microcapsules [24]. 


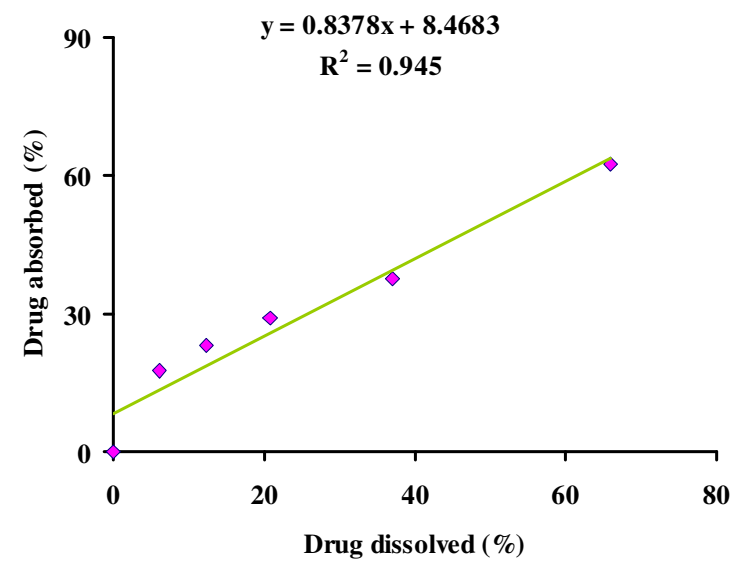

Figure 7. A rectangular coordinate plot between drug absorbed (\%) and drug dissolved (\%) for an optimum formulation $\left(\mathrm{T}_{2}\right)$ of salbutamol sulfate-ethylcellulose tabletted microcapsules.

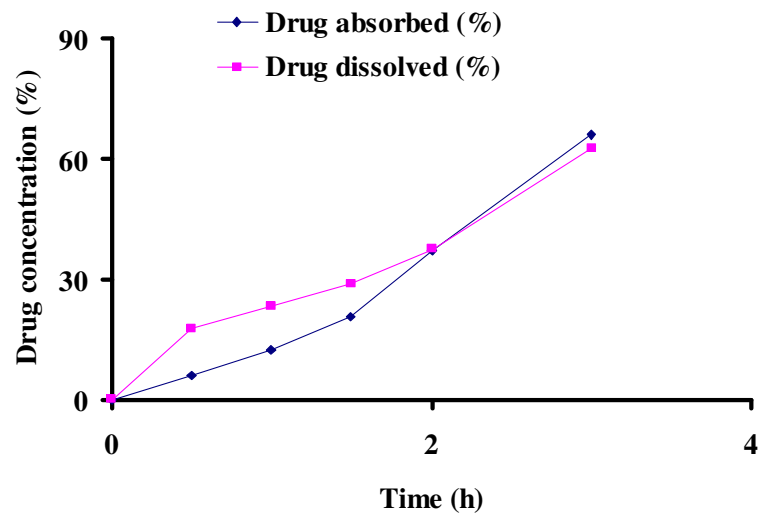

Figure 8. A rectangular coordinate plot of cumulative drug absorbed (\%) and drug dissolved (\%) versus time $(\mathrm{h})$ for an optimum formulation $\left(\mathrm{T}_{2}\right)$ of salbutamol sulfate-ethylcellulose tabletted microcapsules.

Validation of method. The prediction error was found to be less $9.68 \%$ that is within the limits.

\section{CONCLUSIONS}

Non-solvent addition coacervation technique is a good method to encapsulate salbutamol sulfate into the ethylcellulose shells. Moreover, oral tabletted ethylcellulose microcapsules are good sustained release drug delivery system for biowaiver study of BCS class I drugs. 


\section{AKNOWLEDGEMENTS}

The authors are very thankful to Unexo Laboratories for providing generously the sample of salbutamol sulfate. We also thank the research grant of Higher Education Commission, Pakistan, for financial support given to this study.

\section{REFERENCES}

1. Emami, J. J. Pharm. Pharm. Sci. 2006, 9, 169.

2. Nefedova, Y.; Nagaraj, S.; Rosenbauer, A.; Muro-Cacho, C.; Sebti, S.M.; Gabrilovichs, D.I. Cancer Res. 2005, 65, 9525.

3. Amidon, G.L.; Lennernäs, H.; Shah, V.P.; Crison, J.R. Pharm. Res. 1995, 12, 413.

4. Sweetman, S.C.; Reynolds, J.E.F. Martindale-The Extra Pharmacopoeia, 33rd ed., The Royal Pharmaceutical society: London; 2002; p 1014.

5. Rowe, R.C.; Sheskey, R.J.; Weller, P.J. Handbook of Pharmaceutical Excepient, 4th ed., Royal Publishers: London; 2003.

6. Yazan, Y.; Demirel, M.; Guler, E. J. Microencapsul. 1995, 12, 601.

7. Amperiadou, A.; Georgarakis, M. Int. J. Pharm. 1995, 115, 1.

8. Murtaza, G.; Ahmad, M.; Asghar, M.W.; Aamir, M.N. DARU (Iranian J. Tehran University) in press.

9. Sajeev, C.; Vinay, G.; Archna, R.; Saha, R.N. J. Microencapsul. 2002, 19, 753.

10. Hascicek, C.; Gonul, N.; Erk, N. IL Farmaco 2003, 58, 11.

11. Soppimath, K.S.; Kulkarni, A.R.; Aminabhavi, T.M. J. Microencapsul. 2001, 18, 397.

12. British Pharmacopoeia, Appendix XII G, Uniformity of Weight (Mass), Royal Publishers: London; 2004; p 2143.

13. USP30-NF25. The Official Compendium of Standards, 1 May 2007, the United States Pharmacopoeial Convention, 2007; p 56.

14. Khatun, M.; Islam, S.M.A.; Akter, P.; Quadir, M.A.; Reza, M.S. Dhaka Uni. J. Pharm. Sci. 2004, 3,1 .

15. Higuchi, T. J. Pharm. Sci. 1963, 52, 1145.

16. Merchant, H.A.; Shoaib, H.M.; Tazeen, J.; Yousuf, R.I. AAPS PharmSciTech. 2006, 7, E1.

17. Korsmeyer, R.W.; Gurny, R.; Doelker, E.; Buri, P.; Peppas, N.A. Int. J. Pharm. 1983, 15, 25.

18. Koester, L.K.; Ortega, G.G.; Mayorga, P.; Bassani, V.L.Eur. J. Pharm. Biopharm. 2004, 58, 177.

19. Polli, J.E.; Rekhi, G.S. Drug Inform. J. 1996, 30, 1113.

20. Al-Taani, B.M.; Tashtoush, B.M. AAPS PharmSciTech. 2003, 4, E43.

21. Shariff, A.; Manna, P.K.; Paranjothy, K.L.K.; Manjula, M. Pak. J. Pharm. Sci. 2007, 20, 1.

22. Breghausen, S.W.; Schote, U.; Frey, M.; Schmidt, F. J. Control. Release. 2002, 85, 35.

23. Singh, J.; Robinson, D.H. J. Microencapsul. 1990, 7, 67.

24. Ferrari, F.; Bonferoni, M.C.; Rossi, S.; Bertoni, M.; Caramella, C.; Hernandez, R.M.; Pedraz, J.L. Eur. J. Metab. 1993, 18, 5242. 